\title{
Changes in epidemiological patterns of sea lice infestation on farmed Atlantic salmon, Salmo salar L., in Scotland between 1996 and 2006
}

\author{
F Lees $^{1,2}$, G Gettinby ${ }^{1}$ and C W Revie ${ }^{2}$ \\ 1 Department of Statistics and Modelling Science, University of Strathclyde, Glasgow, UK \\ 2 Department of Computer and Information Sciences, University of Strathclyde, Glasgow, UK
}

\begin{abstract}
Analyses of a unique database containing sea lice records over an 11 year period provide evidence of changing infestation patterns in Scotland. The data, collected from more than 50 commercial Atlantic salmon farms, indicate that both species of sea lice commonly found in Scotland, Lepeophtheirus salmonis and Caligus elongatus, have declined on farms over the past decade. Reductions for both species have been particularly marked since 2001 when more effective veterinary medicines became avail able. Treatment data were also available in the database and these show a growing trend towards the use of the in feed medication emamectin ben zoate $\left(\right.$ Slice $\left.{ }^{\circledR}\right)$, particularly in the first year of the salmon production cycle. However, this trend to wards single product use has not been sustained in 2006, the latest year for which data are available. There is some evidence of region to region variation within Scotland with the Western Isles experiencing higher levels of infestation. However, compared to the levels observed between 1996 and 2000, all regions have benefited from reduced lice infestation, with the overall pattern showing a particular reduction in the second and third quarters of the second year of production.
\end{abstract}

Keywords: aquaculture, ectoparasiticide, epidemio logy, Lepeophtheirus salmonis, Salmo salar, Scotland.

Correspondence CW Revie, Department of Statistics and Modelling Science, University of Strathclyde, Richmond Street, Glasgow G1 1XH, UK

(e mail: crawford.revie@cis.strath ac.uk)

\section{Introduction}

Over the last three decades, salmon farming has expanded rapidly and remains one of the fastest growing areas of aquaculture. Since the 1970s, large numbers of farms have been established in Canada, Chile, Norway and Scotland and salmon produc tion now exceeds 1.2 million tonnes per annum world wide (ICES 2006). Throughout this period of expansion, one of the biggest challenges that commercial salmon producers have faced is the threat to fish health and production arising from sea lice infestation (Johnson, Treasurer, Bravo, Nagas awa \& Kabata 2004). The louse species involved and the level of challenge they present vary from country to country, but salmon farms located in most regions are exposed to periodic sea lice infestation.

On the West coast of Scotland, Atlantic salmon, Salmo salar L., are infested by two major species of louse: Lepeophtheirus salmonis (Krøyer, 1837) and Caligus elongatus (Nordmann, 1832). L. salmonis are larger, more abundant and tend to inflict greater damage on the host than C. elongatus (Treasurer \& Grant 1994). While C. elongatus is known to parasitize more than 80 species of fish (Kabata 1979), L. salmonis are largely confined to salmonids, although recent findings suggest that three spined sticklebacks, Gasterosteus aculeatus (L.), also act as hosts (Jones, Prosperi Porta, Kim, Callow \& Hargreaves 2006).

Previous research into sea louse epidemiology (Wootten, Smith \& Needham 1982; Bron, Som merville, Wootten \& Rae 1993a; Revie, Gettinby, Treasurer, Grant \& Reid 2002a; Revie, Gettinby, 
Treasurer \& Rae 2002b) and farm management practices (Bron, Sommerville, Wootten \& Rae 1993b; Grant \& Treasurer 1993; Wadsworth 1998; Rae 2002) in Scotland have led to the development of integrated health management pro grammes that aim to keep lice levels to a minimum throughout the production cycle. Typically, these regimes involve stocking sites with a single genera tion of fish, fallowing farms between production cycles, and routinely monitoring sea lice abundance. However, Scottish salmon farmers still rely on the administration of sea lice medicines when infestation occurs. In recent years, 15 Area Management Agreements (AMAs) have been established between salmon producers and those with interests in wild salmon populations in Scotland. The purpose of these AMAs is to encourage a strategic approach to the management of fish farming activities at a local level, including the control of lice populations through the effective use of ectoparasitic medicines (Scottish Executive 2007).

In 2000 the in feed sea lice medicine, Slice ${ }^{\circledR}$ (active ingredient emamectin benzoate) from Schering Plough Animal Health (Uxbridge, UK), obtained marketing authorization in the UK. The availability of this in feed treatment offered several advantages over traditional labour intensive bath treatments, including the ability to treat during adverse weather conditions, the capacity to medicate all cages on a site simultaneously, and consequently, by the nature of the active ingredient, the potential to obtain extended periods of louse clearance (Stone, Sutherland, Sommerville, Richards \& Varma 2000; Treasurer, Wallace \& Dear 2002; Gustafson, Ellis, Robinson, Marenghi \& Endris 2006).

The only large scale Scottish studies published to date (Revie, Gettinby, Treasurer, Rae \& Clark 2002c; Revie et al. 2002a) focus on data drawn from sea lice populations before Slice ${ }^{\circledR}$ was licensed for use and consequently the extent to which subsequent treatment practices, including their coordinated use within newly formed AMAs, have affected lice levels in Scotland is currently unclear. This study begins to address this gap in knowledge by examining sea lice abundance and treatment data drawn from over 50 Scottish salmon farms, operated by one industrial partner, in the 11 year period since 1996.

\section{Materials and methods}

Sea lice, treatment and stocking data were available for the years 1996 to 2006 from 58 commercial
Atlantic salmon farms located along the West coast of Scotland. All sites were managed by one industrial partner that had adopted a routine sea lice monitoring regime as part of its health management programme.

The number of stocked sites varied throughout the 11 year period depending on the industrial partner's production schedule, but in general each site operated a 2 year production cycle and was stocked with a single year class of fish. A number of sites were stocked with photoperiod manipulated fish as early as October, however typically fish were introduced to each site between January and June in the first year of production, with the second production year running from January of the following year until the fish were harvested between August and February. At some sites, there were a number of separate intakes of fish; however, all sites analysed were stocked with a single generation of fish. Farms that deviated significantly from this schedule, i.e. those that were initially stocked between July and September, were excluded from this analysis. This allowed all louse counts and treatments to be classified as having taken place in either the first or second year of a production cycle. Each site was fallowed for a minimum of 6 weeks before restocking.

Where possible, sea lice levels were monitored weekly throughout the production cycle. At each farm, 1030 fish were randomly sampled from between two and six cages, depending on the number of pens stocked (Treasurer \& Pope 2000). Fish were removed by dip net, anaesthetized and examined for $C$. elongatus mobile stages and for each of five stages of Lepeophtheirus salmonis: chalimus, pre adult, adult male, non gravid female and gravid female. In the analyses presented here the pre adult and adult stages of $L$. salmonis have been aggregated and are reported as L. salmonis mobiles.

As described by Revie et al. (2002a), data available for 1996 to 2000 were screened for quality and consistency to ensure suitability for comparative analysis. These same criteria were applied to data recorded between 2001 and 2006 . Lice count data covering a minimum percentage of weeks that the fish were at sea, in addition to comprehensive treatment and stocking data, were required for a given site year to be eligible for inclusion.

Prior to 2001, count data were recorded at the cage level with each data point representing the 
mean louse abundance on five randomly selected fish per cage. From 2001 onwards, all counts were recorded at the fish level, again typically with five fish randomly selected per pen. To allow proper comparison between the two datasets, all mean abundance figures reported herein are based on sea lice counts summarized to the cage level. All annual and weekly lice abundances were calculated by averaging the cage level values available within the relevant time frame according to the stage in the production cycle.

Between 1996 and 2000, the cage level averages for L. salmonis chalimus stages were doubled in all counts to compensate for potential under reporting. Copepodid and early chalimus stage lice are very small and are therefore difficult to enumerate accurately in the field. With the introduction of a new production database in 2001, this practice was discontinued. To ensure compatibility in chalimus data over the full 11 year period; the practice of doubling chalimus counts was not adopted for any of the data analysed here.

As in an earlier analysis (Revie et al. 2002c), lice data were considered based on regional location. Sites on the West coast of the Scottish mainland were divided above and below $57^{\circ} \mathrm{N}$ and referred to as 'North' and 'South' regions, respectively. Those sites noted as 'Western Isles' included farms on the East coast of South Uist and on both the East and West coasts of Harris and Lewis.

Data were stored and managed using a set of structured tables in Microsoft Access 2003. This application was also used to prepare simple descriptive statistics. All figures were constructed using Microsoft Excel 2003 while statistical anal yses were performed within Minitab 14.1. Statis tical comparison of louse abundance between the first 5 year period and the second, at both stages of production and for each lice species, were undertaken using two sample $t$ tests. Statistical comparison of mean louse abundance (for each site in each year) between geographic regions was undertaken using analysis of variance methods and the GLM procedure followed by pairwise com parisons using Tukey's test. For regional compar isons, the Box Cox procedure indicated that a logarithmic transformation $(\ln (x+1))$ was suitable for comparison of lice counts using the ANOVA procedure. Summarized results are presented using means and $95 \%$ confidence intervals of the untransformed means.

\section{Results}

The data screening process resulted in a final lice count dataset that spanned 11 years, covered 54 farms and consisted of 262 site years: 141 in the first year of production and 121 in the second. As full treatment records were available, even for some sites excluded due to limited lice recording, a total of 184 and 181 site years of treatment data were analysed in the first and second years of production, respectively.

In 2001, the industrial partner changed its production data collection system and, as previously noted, switched to recording louse data at the fish level. During this period of transition, lice count data at some farms were recorded on paper only and not subsequently entered into the industrial part ner's production database. These data were not readily available in a format that could be used within this analysis. Almost all sites from which lice data were available in 2001 did not meet the screening criteria described above. For this reason, no lice data from 2001 are included in Table 1 or in any other abundance analysis presented here.

Once the new production data collection system was in place, high quality fish level lice counts for an adequate number of site years were available for analysis between 2002 and 2006. However, as shown in Table 1 , there was a marked reduction in the number of fish sampled during this 5 year period when compared with fish sampled between 1996 and 2000.

\section{Sea lice abundance}

Table 1 gives the mean abundance of $C$. elongatus mobiles, L. salmonis chalimus and L. salmonis mobiles, on farms in their first and second years of production, in the 5 year period 1996 to 2000 and 2002 to 2006.

In both 5 year periods, $C$. elongatus abundance was higher in the first year of production than in the second, a pattern reported in previous studies (Revie et al. 2002a,c). However, at both stages of the production cycle, levels of $C$. elongatus mobiles had dropped significantly $(P<0.01)$ in the second 5 year period. In the first year of the production cycle, $C$. elongatus levels were similar to those seen for the mobile stages of $L$. salmonis, while in the second year L. salmonis mobiles were around eight times more abundant. No detailed epidemiological patterns for $C$. elongatus are reported. 
Table 1 A comparison of the mean abundance of Caligus elongatus and Lepeophtheirus salmonis sea lice per fish and the numbers of sites, site years, cages and fish sampled in the first and second year of the production cycle of Atlantic salmon between the periods 1996-2000 and 2002-2006

\begin{tabular}{|c|c|c|c|c|c|c|c|}
\hline & & \multicolumn{3}{|c|}{ First year of production } & \multicolumn{3}{|c|}{ Second year of production } \\
\hline & & 19962000 & 20022006 & $\begin{array}{l}\text { Reduction } \\
{[95 \% \mathrm{Cl}]}\end{array}$ & 19962000 & 20022006 & $\begin{array}{l}\text { Reduction } \\
{[95 \% \mathrm{Cl}]}\end{array}$ \\
\hline \multirow[t]{2}{*}{ C elongatus mobiles } & Mean & 3.5 & 1.5 & $2.0\left[\begin{array}{ll}1.8 & 2.2\end{array}\right]$ & 1.6 & 0.4 & $1.1\left[\begin{array}{ll}1.0 & 1.3\end{array}\right]$ \\
\hline & $\mathrm{SD}$ & 6.5 & 4.0 & & 3.6 & 2.4 & \\
\hline \multirow{2}{*}{ L salmonis chalimus } & Mean & 1.7 & 0.7 & $0.9\left[\begin{array}{ll}0.8 & 1.0\end{array}\right]$ & 5.4 & 1.3 & $4.1\left[\begin{array}{ll}3.9 & 4.4\end{array}\right]$ \\
\hline & SD & 3.0 & 1.9 & & 7.9 & 4.6 & \\
\hline \multirow[t]{6}{*}{ L salmonis mobiles } & Mean & 3.9 & 1.6 & $2.3\left[\begin{array}{ll}2.1 & 2.5\end{array}\right]$ & 14.0 & 3.6 & $10.4\left[\begin{array}{ll}10.0 & 10.8\end{array}\right]$ \\
\hline & SD & 7.7 & 3.8 & & 15.2 & 7.1 & \\
\hline & Sites & 33 & 45 & & 28 & 43 & \\
\hline & Site years & 65 & 76 & & 51 & 70 & \\
\hline & Cages & 6972 & 4777 & & 7348 & 3999 & \\
\hline & Fish ('000s) & 34.9 & 25.1 & & 36.7 & 20.8 & \\
\hline
\end{tabular}

Mean and SD values based on data are summarized to the cage level.

In the period 1996 to 2000, L. salmonis chalimus and mobile abundances were more than three times higher in the second year of production than in the first. Between 2002 and 2006, L. salmonis levels remained higher in the second year of production; however, the difference between the first and second years was less marked. The standard deviations reported in Table 1 indicate that louse levels in each 5 year period were highly variable; however, chal imus and mobile levels, at both stages of the production cycle, were observed to be significantly lower $(P<0.01)$ in 2002 to 2006 when compared to those in the first 5 year period. In all cases, the levels of mobile infection observed for $L$. salmonis were around 2.5 times those observed for the chalimus stages.

Fig. 1a, b shows the mean annual abundance of L. salmonis chalimus and mobiles between 1996 and 2006, on farms in their first and second years of production (with 2001 omitted for reasons previ ously discussed).

With the exception of 2005 and 2006, chalimus abundance was higher in the second year of production than in the first. In 1996 to 2000, mean chalimus abundance in the second year of production was consistently above five lice per fish, the only exception being in 1997 when mean abundance fell to 4.3. After 2001, chalimus levels did not rise above 2.7 and fell to around 0.3 lice per fish in 2005 and 2006 in the second year of production.

The change in mobile abundance was also pronounced. In the second year of production, mean mobile abundance fell year on year from a peak in 1998, when levels reached 17.5 lice per fish,
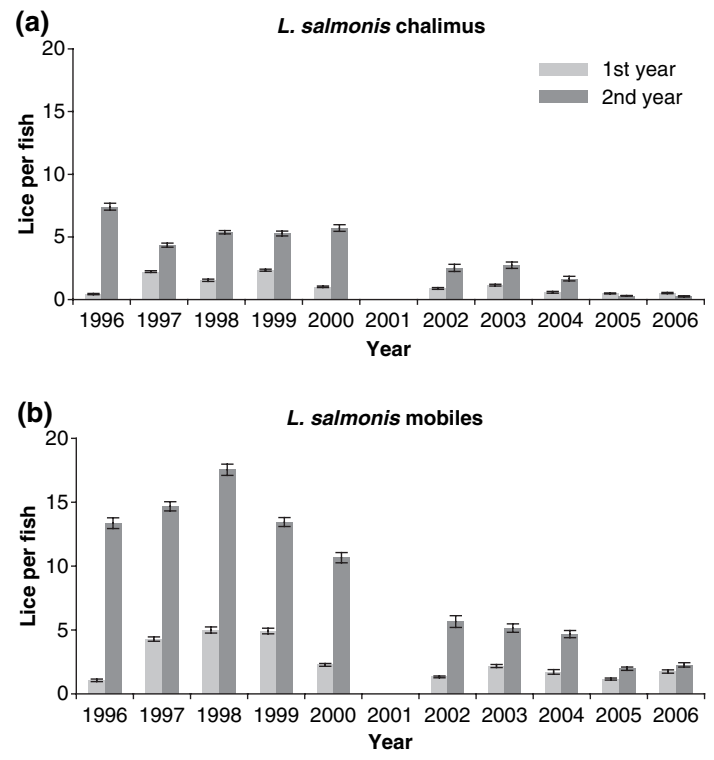

Figure 1 Mean abundance $( \pm \mathrm{SE})$ of (a) Lepeophtheirus salmonis chalimus and (b) Lepeophtheirus salmonis mobile sea lice per fish each year between 1996 and 2006, except 2001, in the first and second year of each production cycle of Atlantic salmon.

until 2005 when levels fell to two lice per fish. In 2006, abundance rose slightly to 2.3 mobile lice per fish. Mobile abundance in the first year of produc tion also decreased, albeit to a lesser extent, with levels of around five lice per fish in 1998 and 1999, falling to 1.2 in 2005 .

\section{Sea lice seasonal variations}

While Fig. 1 is useful in identifying year on year changes in lice abundance, it does not show the 
seasonal variation observed in lice levels throughout the 2 year production cycle. Fig. 2a, b compares mean abundance, by calendar week, observed over the 2 year production cycle for L. salmonis chalimus and mobiles in the 5 year periods 1996 to 2000 and 2002 to 2006.

Between 1996 and 2000, chalimus and mobile levels remained low until the final quarter of the first year, whereupon they began to rise until the end of the first quarter of the following year. Following a dip in abundance around week 64 (late March), there was a strong upward trend, partic ularly evident for the mobile stages, interspersed with sharp fluctuations in lice levels until the fish were harvested at the end of the year. During the final 6 months of production chalimus peaks were in the region of nine lice per fish, with mobile abundance peaking at between 20 and 30 lice.

In the period 2002 2006, the first year of the production cycle was largely unchanged with chal imus and mobile levels remaining low until the final quarter. While abundance did increase until week 64 in the second year, levels were around half that found in the earlier 5 year period. In contrast to 1996 to 2000, mobile levels did not continue to rise throughout the second year, but declined and remained below five lice per fish until harvest, with the exception of week 101. In this week, mean

(a)

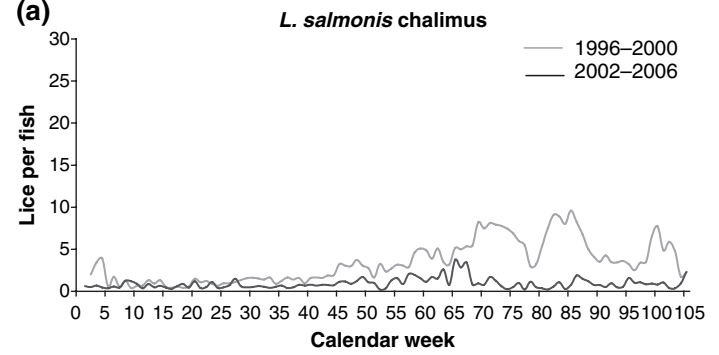

(b)

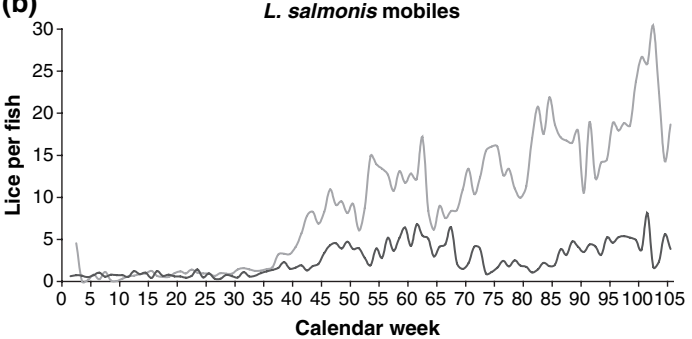

Figure 2 Mean weekly abundance of (a) Lepeophtheirus salmonis chalimus and (b) Lepeophtheirus salmonis mobile sea lice per fish over the 2-year production cycle of Atlantic salmon between 1996-2000 and 2002-2006. abundance reached 8.1 mobiles as a result of exceptionally high infection on a single site. Chalimus abundance peaked at four lice per fish in weeks 6567 (early April), after which it fell and remained below two for the rest of the production cycle.

\section{Regional variation}

The data from the 54 sites were classified according to three main regions of salmon production in Scotland: North (21), South (13) and Western Isles (20). Each of these areas is operated as a separate geographical region by the industrial partner. Using this regional classification, Fig. 3 a $\mathrm{c}$ shows the mean annual abundance of $L$. salmonis mobiles between 1996 and 2006 on farms in their first and second year of production.
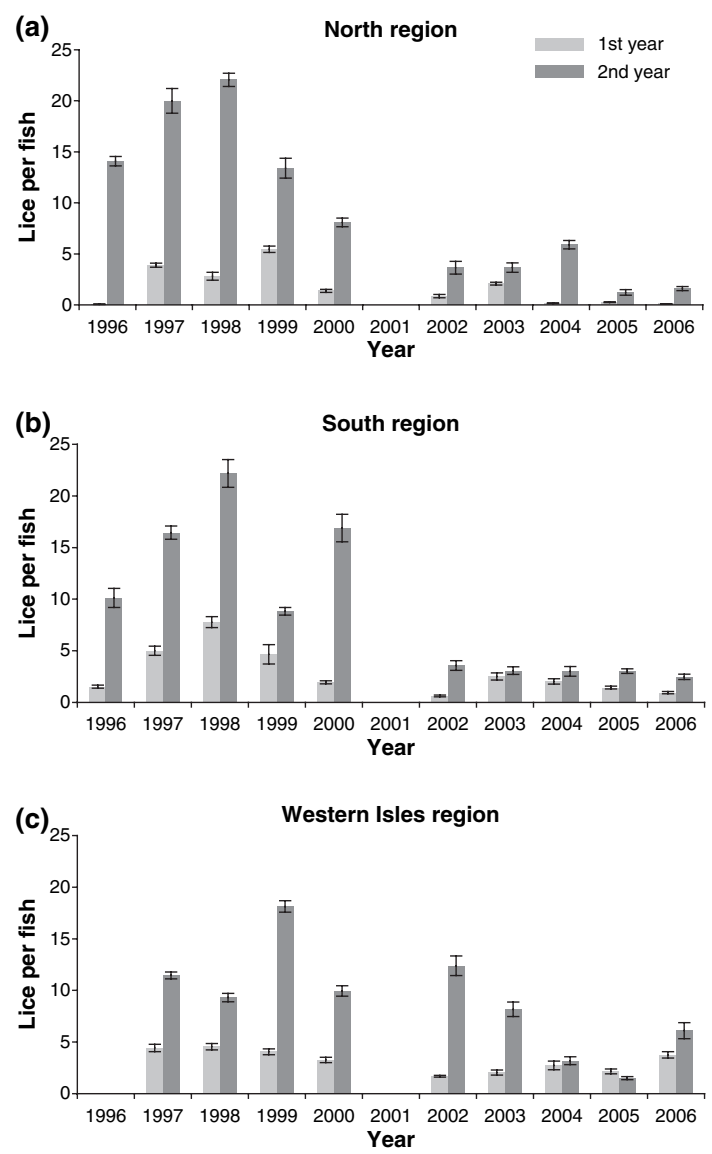

Figure $3(\mathrm{a}-\mathrm{c})$ Mean abundance $( \pm \mathrm{SE})$ of Lepeophtheirus salmonis mobile sea lice per fish by geographical region each year between 1996 and 2006, except 2001, in the first and second year of each production cycle of Atlantic salmon. 
Annual levels of mobile infestation in the North and South were broadly in line with the overall pattern for all regions and both areas observed a marked decline in lice levels after 2001. In the second year of production, mobile abundance in the North declined from 8.1 in 2000 to around 3.7 in 2002 2003, rose to 5.9 in 2004 and then dropped below 2 mobiles per fish in 2005 2006. Mobile abundance in the South dropped considerably from 16.9 in 2000 to 3.6 in 2002 and remained around 3 lice per fish thereafter.

The Western Isles appear to present a different picture. Historically mobile levels appeared lower in this region than in the other two, although not significantly so (Revie et al. 2002c). In the second year of production, mobile abundance was higher, at 12.4, in 2002 than in any other year except 1999 and abundance was still as high as 8.2 in 2003 . This contrasts sharply with findings in the other two regions. While mobile levels did fall below 3.2 per fish in 2004 2005, they rose again to more than five in 2006. It is also interesting to note that in 2005 mobile levels in the second year of production were lower than those in the first a phenomenon not observed in any other year or in any other region.

In 2002 to 2006, mobile levels on farms in the Western Isles were significantly higher than on sites in the North region. This was the case in the first year of production $(P<0.01$, difference 1.7 lice, $95 \%$ CI $[0.23 .2])$ as well as in the second $(P=0.048$, difference 2.7 lice, $95 \%$ CI $[0.2$

5.1]). No other significant differences in mobile lice levels were found between any other regions.

Fig. 4a, b compares the mean weekly abundance of $L$. salmonis mobiles in each of the regions over the 2 year production cycle in the 5 year period 1996 to 2000 and 2002 to 2006. Between 1996 and 2000, the pattern of mobile abundance was broadly similar across all three regions, with abundance in the South peaking at the highest levels and the Western Isles appearing to exhibit a slightly lower level than the other two regions. Mobile abundance was noticeably lower in all three regions in the second 5 year period; however, levels in the Western Isles were higher than in the other two regions in most weeks throughout the entire 2 year production cycle.

\section{Sea lice treatments}

Ectoparasiticides administered to control sea lice burdens changed considerably over the 11 year period and, as can be seen from Fig. 5a \& b, varied
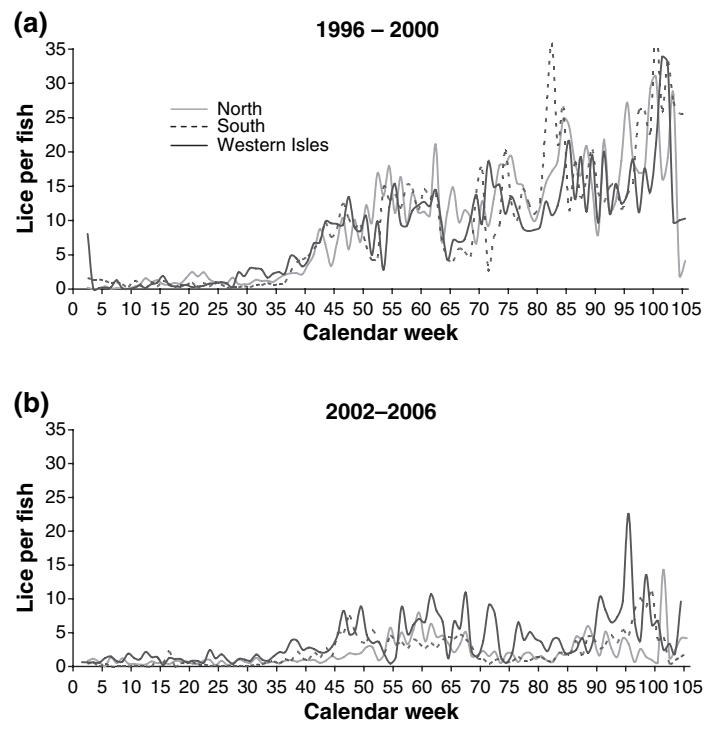

Figure 4 Mean weekly abundance of Lepeophtheirus salmonis mobile sea lice per fish by geographical region over the 2-year production cycle of Atlantic salmon between (a) 1996-2000 and (b) 2002-2006.
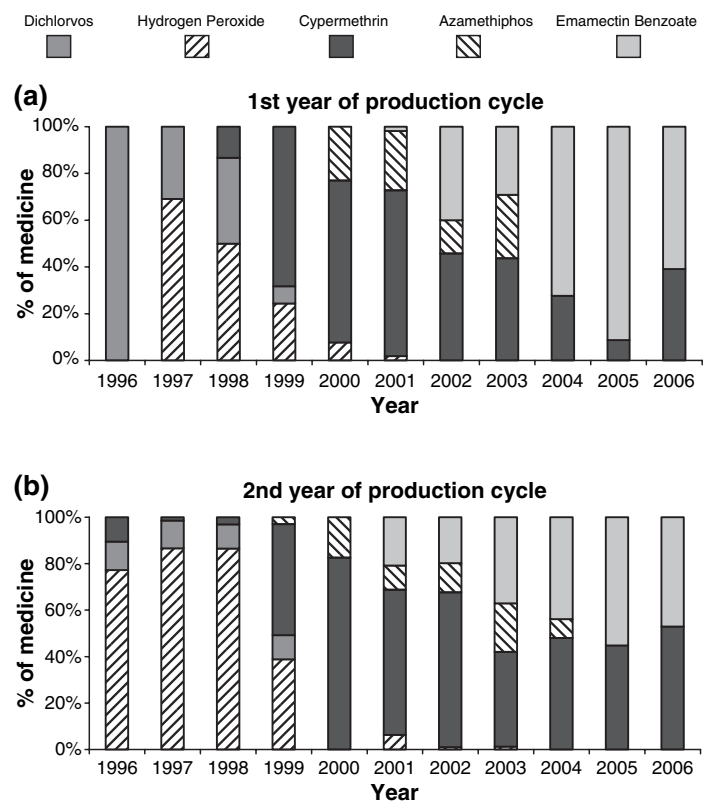

Figure 5 Proportion of sea lice treatments given, by medicine type, each year between 1996 and 2006 in the (a) first and (b) second year of each production cycle of Atlantic salmon, based on 1149 treatment episodes over 365 site years.

depending on the stage of the production cycle. It should be noted that the percentages shown in Fig. 5 are based on the number of times a medicine was used and not on the absolute quantity admin 
istered. No differentiation has been made between treatment events where a site was fully treated and those that relate to partial treatments; however, fewer than $10 \%$ of the 1149 treatment episodes reviewed were partial site treatments.

From 1996 until 1998, dichlorvos (Aquagard ${ }^{\circledR}$ : Novartis Animal Health UK Ltd, Camberley, UK) and hydrogen peroxide (Salartec ${ }^{\circledR}$ : Brenntag Ltd, Kingswinford, UK) were used almost exclusively in both the first and second years of production, with cypermethrin (Excis ${ }^{\circledR}$ : Novartis) making up the small remainder of treatments. Following the withdrawal of its marketing authorization in 1999, dichlorvos treatments ceased and another organophosphate, azamethiphos (Salmosan ${ }^{\circledR}$ : Novartis), came into use and accounted for up to $20 \%$ of treatments until 2003. However, from 1999 the industrial partner also began to move away from organophosphate based compounds and increasingly administered the synthetic pyrethroid cypermethrin $\left(\right.$ Excis $\left.^{\circledR}\right)$.

The semi synthetic avermectin $\left(\right.$ Slice ${ }^{\circledR}$ ) was licensed for use in the UK in 2000, but was not used on any of the sites studied until February 2001. In contrast to all previous medicines, this compound is given as an in feed rather than a bath treatment. Between 2002 and 2005, the use of this compound increased dramatically year on year; however, this trend was not sustained in 2006. Since 2004 treatments have been based on the exclusive use of Slice ${ }^{\circledR}$ and Excis ${ }^{\circledR}$, except for the very limited use of Salmosan ${ }^{\circledR}$ in 2004 on fish in their second year of production.

In 2004 and 2005 , Slice ${ }^{\circledR}$ was used very widely in the first production year, accounting for $72 \%$ and $91 \%$ of treatments, respectively. It was used regu larly, but less frequently in the second year when Excis ${ }^{\circledR}$ became more prominent toward the end of the production cycle. Treatment patterns in 2006 changed again. In this most recent year, Excis ${ }^{\circledR}$ became more prominent, accounting for 39\% of treatment episodes in the first production year and $53 \%$ in the second. Slice ${ }^{\circledR}$ usage fell at both stages of production, but most notably in the first year.

The only other in feed treatment available, teflu benzuron (Calicide ${ }^{\circledR}$ : Skretting, Northwich, UK), was seldom used accounting for less than $0.5 \%$ of sea lice treatments administered over the 11 year period.

\section{Discussion}

The results of the present study, based on data from more than 50 commercial salmon farms located along the West coast of Scotland between 1996 and 2006, clearly show that there has been a notable change in sea lice abundance, infestation patterns and ectoparasiticide use over the 11 year period studied. While all data were provided by a single industrial partner, they are believed to be a fair representation of the region as a whole. Individual sites were dispersed along the West coast and accounted for around $20 \%$ of total Scottish production during the period.

Although a routine sea lice monitoring pro gramme was in place throughout the period of study, proportionally fewer fish were sampled from 2002 onwards. This was particularly the case in the second year, which is surprising given that lice pressure has historically been observed to be greatest at this stage in production (Revie et al. 2002a,c). However, the number of weeks per year in which lice counts took place did not vary greatly between each 5 year period, indicating that lice levels continued to be monitored regularly after 2001, albeit with fewer fish and cages at each sample point. This coincided with the introduction of a new production data collection system that shifted the responsibility for lice data entry to trained and qualified staff based on farms and away from dedicated members of administration staff. How ever, the reduced number of fish sampled also reflects the fact that lower levels of lice were found from 2002 onwards and health observers felt that sampling from fewer pens was sufficient to obtain an overall picture of lice infestation on each farm. Recent publications (Revie, Gettinby, Treasurer \& Wallace 2005a; Revie, Hollinger, Gettinby, Lees \& Heuch 2007) reported that significant levels of clustering can occur within and between cages. It is therefore important that health observers continue to sample as many cages as feasible in order to obtain a precise estimate of mean lice abundance, even when lice abundance appears to be low.

Comparing the period 19962000 with 2002 2006 there was a statistically significant drop in lice abundance at both stages of the production cycle. Lepeophtheirus salmonis remained the predominant species of louse observed on farmed Atlantic salmon in Scotland. It is interesting to note that while levels of both lice species declined, the ratio of C. elongatus mobiles to L. salmonis mobiles, at each stage of the production cycle, remained remarkably consistent for both 5 year periods.

Previous reports have noted that levels of lice abundance in Scotland were considerably higher 
than those observed in Norway (Heuch, Revie \& Gettinby 2003) and the Broughton Archipelago on the West coast of Canada (Saksida, Constantine, Karreman \& Donald 2007a). Typically, these reports compare data gathered in regions where in feed treatments were available for use, against Scottish data recorded before marketing authoriza tion was obtained for Slice ${ }^{\circledR}$. When considering the period since Slice ${ }^{\circledR}$ became available (2002 2006), the abundance of L. salmonis observed in Scotland would appear to be similar to that reported on farms stocking Atlantic salmon in the Broughton Archipelago (Saksida, Constantine, Karreman \& Donald 2007b).

The epidemiological signature of $L$. salmonis over the 2 year production cycle, for 1996 to 2000, has been documented in earlier Scottish studies (Revie et al. 2002a,c). Perhaps the most striking difference in lice infestation patterns for the years 2002 to 2006, when compared to the earlier 5 year period, is the marked reduction in abundance through the summer months of the second production year. A number of authors have highlighted the potential risk to wild smolts presented by a high level of challenge from fish farms during their second year of production (Butler 2002; McKibben \& Hay 2004). The reduction in lice abundance observed subsequent to 2001 may help address this concern. This may have been partly due to the strategic treatment regime adopted on many sites in the spring of the second year as part of the Area Management Agreement (AMA) process. Prior to 2001, attempts had been made to introduce strategic treatments; however, the limitations of sea lice medicines available at that time appeared to compromise the ability of strategic interventions to provide area wide benefits (Revie, Gettinby, Trea surer \& Wallace 2003).

The significant decline in L. salmonis abundance and the changes in pattern of infestation coincide with a change in the availability and use of ectoparasitic medicines. In the early years of the study, treatment alternatives were limited to orga nophosphate compounds and hydrogen peroxide. Conversely by 2005, Excis ${ }^{\circledR}$ and Slice ${ }^{\circledR}$ were the only sea lice medicines, with Slice ${ }^{\circledR}$ being used extensively in the first year of production. As an in feed treatment, this medicine becomes more expen sive to administer as fish weight increases which partly explains why Excis ${ }^{\circledR}$ bath treatments become more frequent toward the end of the second production year. Reliance on a limited number of sea lice medicines has raised concerns that lice resistance will increasingly become a problem on salmon farms (Denholm, Devine, Horsberg, Sevat dal, Fallang, Nolan \& Powell 2002; Westcott, Hammell \& Burka 2004). The Scottish Salmon Producers Organisation (SSPO) raised this issue in its recent 4 year plan (SSPO 2007) in support of its request that another compound, deltamethrin (Al phaMax ${ }^{\circledR}$ : Pharmaq Ltd, Fordingbridge, UK), be licensed for use in Scotland. AlphaMax ${ }^{\circledR}$ has been available in Norway since 1998 (Roth 2000) and was recently granted a full marketing authorization. It is also authorized for limited use on farms in Ireland (G. Ritchie, personal communication). The potential of sea lice becoming resistant to currently available medicines remains a key area of research that is of critical importance to all countries with an aquaculture industry, as are strategies to manage any such resistance. It is encouraging to note that the increasing reliance on only one active ingredient was less marked in the most recent year for which data are available. This may be an indication of the adoption of strategic product rotation.

Despite a significant decline in lice abundance overall, the results presented indicate that not all geographical areas experienced as marked a reduc tion in lice levels. Between 2002 and 2006, farms located within the Western Isles region had signif icantly higher levels of $L$. salmonis than those in the North. This was not the case in the earlier 5 year period (Revie et al. 2002c). There appears to be evidence of synchronized treatments across the Western Isles with marked reductions in lice abundance evident in weeks 64, 69 and 74 . However, these still do not appear to control lice levels throughout the summer period as effectively as seen elsewhere in Scotland.

The level of treatment and type of medicine used was a major determinant of lice abundance seen in Scotland between 1996 and 2000 (Revie et al. 2003). However, a judgement as to the relative importance of treatment and other factors, such as the newly established management practices within AMAs, in the more recent period of study must await further analysis of all risk factors.

In the work presented to date on lice in Scottish salmon farms, discussion has focused on abundance as the most appropriate measure. This was partly due to the fact that historically a large proportion of farmed fish sampled had at least some lice present (J.W. Treasurer, personal communication), i.e. prevalence was close to $100 \%$ and thus intensity 
and abundance tended towards the same value (Bush, Lafferty, Lotz \& Shostak 1997). This observation was similar to that seen for infestations on wild salmon (Todd, Walker, Hoyle, Northcott, Walker \& Ritchie 2000) and is highly unusual among ectoparasitic species (Shaw \& Dobson 1995). However, the more recent data exhibit lower levels of prevalence (between $3570 \%$ depending on year and period of production) and thus abundance alone may no longer be an entirely adequate measure by which to summarize these data. Abundance has been used in this paper to maintain historical compatibility, but further anal yses of risk factors and other aspects of population modelling (Revie, Robbins, Gettinby, Kelly \& Treasurer 2005b) using the most recent dataset will consider the issue of prevalence more fully.

\section{Acknowledgements}

The database underpinning this work was created as part of two UK government funded research projects (MAFF LINK, ENV12; DEFRA, VM0213). The industrial partner was Marine Harvest (Scotland). Thanks are due to all admin istrative and farm management staff who contrib uted to this project and in particular to the regional health managers; Carol Cox, Alisdair MacLennan and Chris Wallace. The authors wish to thank Gordon Ritchie of Marine Harvest for his com ments and suggestions during the preparation of the manuscript.

\section{References}

Bron J.E., Sommerville C., Wootten R. \& Rae G.H. (1993a) Influence of treatment with dichlorvos on the epidemiology of Lepeophtheirus salmonis (Krøyer, 1837) and Caligus elongatus (Nordmann, 1832) on Scottish salmon farms. In: Pathogens of Wild and Farmed Fish: Sea Lice (ed. by G.A. Boxshall \& D. Defaye), pp. 263-274. Ellis Horwood, Chichester.

Bron J.E., Sommerville C., Wootten R. \& Rae G.H. (1993b) Fallowing of marine Atlantic salmon, Salmo salar L., farms as a method for the control of sea lice, Lepeophtheirus salmonis (Krøyer, 1837). Journal of Fish Diseases 16, 487-493.

Bush A.O., Lafferty K.D., Lotz J.M. \& Shostak A.W. (1997) Parasitology meets ecology on its own terms: Margolis et al. revisited. Journal of Parasitology 83, 575-583.

Butler J.R.A. (2002) Wild salmonids and sea louse infestations on the west coast of Scotland: sources of infection and implications for the management of marine salmon farms. Pest Management Science 58, 595-608.

Denholm I., Devine G.J., Horsberg T.E., Sevatdal S., Fallang A., Nolan D.V. \& Powell R. (2002) Analysis and management of resistance to chemotherapeutants in salmon lice, Lepeophtheirus salmonis (Copepoda: Caligidae). Pest Management Science 58, 528-536.

Grant A.N. \& Treasurer J.W. (1993) The effects of fallowing on caligid infestations on farmed salmon (Salmo salar L.) in Scotland. In: Pathogens of Wild and Farmed Fish: Sea Lice (ed. by G.A. Boxshall \& D. Defaye), pp. 255-260. Ellis Horwood, Chichester.

Gustafson L., Ellis S., Robinson T., Marenghi F. \& Endris R. (2006) Efficacy of emamectin benzoate against sea lice infestations of Atlantic salmon, Salmo salar L.: evaluation in the absence of an untreated contemporary control. Journal of Fish Diseases 29, 621-627.

Heuch P.A., Revie C.W. \& Gettinby G. (2003) A comparison of epidemiological patterns of salmon lice, Lepeophtheirus salmonis, infections on farmed Atlantic salmon, Salmo salar L., in Norway and Scotland. Journal of Fish Diseases 26, 539-551.

ICES (2006) Report of the Working Group on North Atlantic Salmon. ICES CM 2006/ACFM:23, 254 pp.

Johnson S.C., Treasurer J.W., Bravo S., Nagasawa K. \& Kabata Z. (2004) A review of the impact of parasitic copepods on marine aquaculture. Zoological Studies 43, 229-243.

Jones S.R.M., Prosperi-Porta G., Kim E., Callow P. \& Hargreaves N.B. (2006) The occurrence of Lepeophtheirus salmonis and Caligus clemensi (Copepoda: Caligidae) on three-spine stickleback Gasterosteus aculeatus in coastal British Columbia. Journal of Parasitology 92, 473-480.

Kabata Z. (1979) Parasitic Copepoda of British Fishes. The Ray Society, London, UK.

McKibben M.A. \& Hay D.W. (2004) Distributions of planktonic sea lice larvae Lepeophtheirus salmonis in the inter-tidal zone in Loch Torridon, western Scotland in relation to salmon farm production cycles. Aquaculture Research 35, 742-750.

Rae G.H. (2002) Sea louse control in Scotland, past and present. Pest Management Science 58, 515-520.

Revie C.W., Gettinby G., Treasurer J.W., Grant A.N. \& Reid S.W.J. (2002a) Sea lice infestations on farmed Atlantic salmon in Scotland and the use of ectoparasitic treatments. The Veterinary Record 151, 753-757.

Revie C.W., Gettinby G., Treasurer J.W. \& Rae G.H. (2002b) The epidemiology of the sea lice, Caligus elongatus Nordmann, in marine aquaculture of Atlantic salmon, Salmo salar L., in Scotland. Journal of Fish Diseases 25, 391-399.

Revie C.W., Gettinby G., Treasurer J.W., Rae G. \& Clark N. (2002c) Temporal, environmental and management factors influencing the epidemiological patterns of sea lice (Lepeophtheirus salmonis) infestations on farmed Atlantic salmon (Salmo salar) in Scotland. Pest Management Science 58, 576584.

Revie C.W., Gettinby G., Treasurer J.W. \& Wallace C. (2003) Identifying epidemiological factors affecting sea lice Lepeophtheirus salmonis abundance on Scottish salmon farms using general linear models. Diseases of Aquatic Organisms 57, 8595.

Revie C.W., Gettinby G., Treasurer J.W. \& Wallace C. (2005a) Evaluating the effect of clustering when monitoring the abundance of sea lice populations on farmed Atlantic salmon. Journal of Fish Biology 66, 773-783. 
Revie C.W., Robbins C., Gettinby G., Kelly L. \& Treasurer J.W. (2005b) A mathematical model of the growth of sea lice, Lepeophtheirus salmonis, populations on farmed Atlantic salmon, Salmo salar L., in Scotland and its use in the assessment of treatment strategies. Journal of Fish Diseases 28, 603-613.

Revie C.W., Hollinger E., Gettinby G., Lees F. \& Heuch P.A. (2007) Clustering of parasites within cages on Scottish and Norwegian salmon farms: alternative sampling strategies illustrated using simulation. Preventative Veterinary Medicine $\mathbf{8 1}, 135-147$.

Roth M. (2000) The availability and use of chemotherapeutic sea lice products. Contributions to Zoology 69, 109-118.

Saksida S., Constantine J., Karreman G.A. \& Donald A. (2007a) Evaluation of sea lice abundance levels on farmed Atlantic salmon (Salmo salar L.) located in the Broughton Archipelago of British Columbia from 2003 to 2005. Aquaculture Research 38, 219-231.

Saksida S., Constantine J., Karreman G.A. \& Donald A. (2007b) Differences in Lepeophtheirus salmonis levels on Atlantic salmon farms in the Broughton Archipelago, British Columbia, Canada. Journal of Fish Diseases 30, 357-366.

Scottish Executive (2007) Tripartite Working Group - Area Management Agreements. Available at http://www.scotland.gov.uk/Topics/Fisheries/Fish-Shellfish/18677/14221

Shaw D.J. \& Dobson A.P. (1995) Patterns of macroparasite abundance and aggregation in wildlife populations: a quantitative review. Parasitology 111, S111-S133.

SSPO (2007) Developing Salmon Farming, Protecting the Environment. Ways of Improving the Salmon Farming Industry: A Plan for the Next Four Years. The Scottish Salmon Producers Organisation, Perth, Scotland. Available at http://www. scottishsalmon.co.uk/mediacentre/releases/2007/documents/ SSPO-DevelopingSalmonFarmingProtectingtheEnvironment. FINAL.doc

Stone J., Sutherland I.H., Sommerville C., Richards R.H. \& Varma K.J. (2000) Commercial trials using emamectin benzoate to control sea lice Lepeophtheirus salmonis infestations in Atlantic salmon Salmo salar. Diseases of Aquatic Organisms 41, 141-149.

Todd C.D., Walker A.M., Hoyle J.E., Northcott S.J., Walker A.F. \& Ritchie M.G. (2000) Infestations of wild adult Atlantic salmon (Salmo salar L.) by the ectoparasitic copepod sea louse Lepeophtheirus salmonis Krøyer: prevalence, intensity and the spatial distribution of males and females on the host fish. Hydrobiologia 429, 181-196.

Treasurer J. \& Grant A. (1994) 'Second' louse species must not be ignored. Fish Farmer 17, 46-47.

Treasurer J.W. \& Pope J.A. (2000) Selection of host sample number and design of a monitoring programme for ectoparasitic sea lice (Copepoda: Caligidae) on farmed Atlantic salmon, Salmo salar. Aquaculture 187, 247-260.

Treasurer J.W., Wallace C. \& Dear G. (2002) Control of sea lice on farmed Atlantic salmon S. salar L., with the oral treatment emamectin benzoate $\left(\mathrm{SLICE}^{\circledR}\right)$. Bulletin of the European Association of Fish Pathologists 22, 375-380.

Wadsworth S.L. (1998) The Control of Lepeophtheirus salmonis (Krøyer, 1837) (Copepoda: Caligidae) on Atlantic salmon Salmo salar $\mathrm{L}$ production sites. $\mathrm{PhD}$ thesis, University of Aberdeen, UK

Westcott J.D., Hammell K.L. \& Burka J.F. (2004) Sea lice treatments, management practices and sea lice sampling methods on Atlantic salmon farms in the Bay of Fundy, New Brunswick, Canada. Aquaculture Research 35, 784-792.

Wootten R., Smith J.W. \& Needham E.A. (1982) Aspects of the biology of the parasitic copepods Lepeophtheirus salmonis and Caligus elongatus on farmed salmonids, and their treatment. Proceedings of the Royal Society of Edinburgh 81B, 185-197. 